\title{
Philosophy and Medicine
}

\section{Volume 125}

\section{Founding Co-Editor}

Stuart F. Spicker

\section{Senior Editor}

H. Tristram Engelhardt, Jr., Department of Philosophy, Rice University, and Baylor College of Medicine, Houston, TX, USA

\section{Series Editor}

Lisa M. Rasmussen, Department of Philosophy, University of North Carolina at Charlotte, Charlotte, NC, USA

\section{Assistant Editor}

Jeffrey P. Bishop, Gnaegi Center for Health Care Ethics, Saint Louis University, St. Louis, MO, USA

\section{Editorial Board}

George J. Agich, Department of Philosophy, Bowling Green State University, Bowling Green, OH, USA

Nicholas Capaldi, College of Business Administration, Loyola University,

New Orleans, LA, USA

Edmund Erde, University of Medicine and Dentistry of New Jersey (Retired), Stratford, NJ, USA

Christopher Tollefsen, Department of Philosophy, University of South Carolina, Columbia, SC, USA

Kevin Wm. Wildes, S.J., President, Loyola University, New Orleans, LA, USA 
More information about this series at http://www.springer.com/series/6414 
Lisa M. Rasmussen • Ana Smith Iltis Mark J. Cherry

Editors

At the Foundations of Bioethics and Biopolitics: Critical Essays on the Thought of H. Tristram Engelhardt, Jr.

Springer 


\section{Editors}

Lisa M. Rasmussen

Department of Philosophy

University of North Carolina

Charlotte, NC, USA

\author{
Mark J. Cherry \\ Department of Philosophy \\ St. Edward's University \\ Austin, TX, USA
}

\author{
Ana Smith Iltis \\ Department of Philosophy \\ Center for Bioethics, Health and Society \\ Wake Forest University \\ Winston-Salem, NC, USA
}

ISSN 0376-7418

Philosophy and Medicine

ISBN 978-3-319-18964-2

DOI 10.1007/978-3-319-18965-9

\section{Library of Congress Control Number: 2015952778}

Springer Cham Heidelberg New York Dordrecht London

(C) Springer International Publishing Switzerland 2015

This work is subject to copyright. All rights are reserved by the Publisher, whether the whole or part of the material is concerned, specifically the rights of translation, reprinting, reuse of illustrations, recitation, broadcasting, reproduction on microfilms or in any other physical way, and transmission or information storage and retrieval, electronic adaptation, computer software, or by similar or dissimilar methodology now known or hereafter developed.

The use of general descriptive names, registered names, trademarks, service marks, etc. in this publication does not imply, even in the absence of a specific statement, that such names are exempt from the relevant protective laws and regulations and therefore free for general use.

The publisher, the authors and the editors are safe to assume that the advice and information in this book are believed to be true and accurate at the date of publication. Neither the publisher nor the authors or the editors give a warranty, express or implied, with respect to the material contained herein or for any errors or omissions that may have been made.

Printed on acid-free paper

Springer International Publishing AG Switzerland is part of Springer Science+Business Media (www.springer.com) 
Mine is to chew on the appropriate texts and make them delectable.

- St. Gregory of Nyssa (335-394 or 395)

To our mentor,

Professor Doctor H. Tristram Engelhardt, Jr., Ph.D., M.D., for training in the chewing of texts and ideas

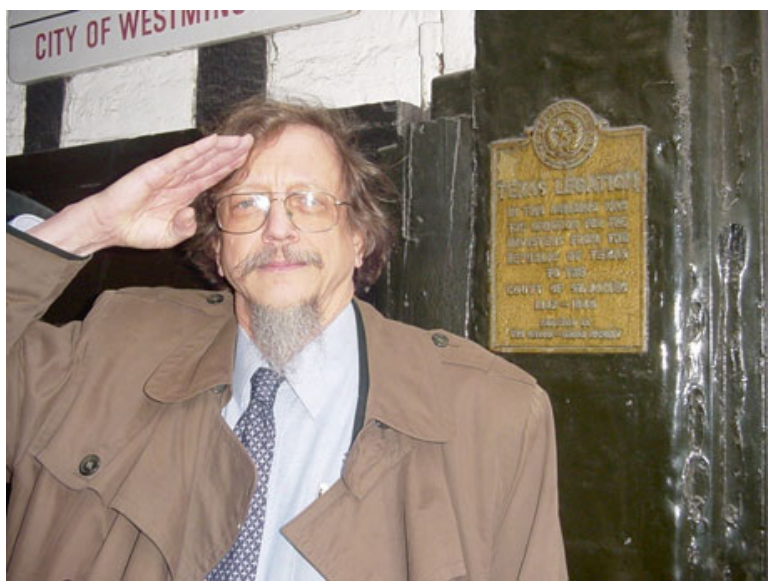

Dr. H. Tristram Engelhardt, Jr. paying tribute to the Republic of Texas near a plaque commemorating its former embassy building in London, England. Photo courtesy of Jeremy Garrett. 



\section{Contents}

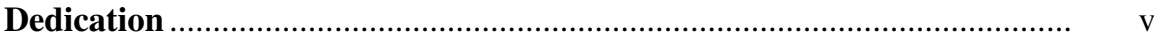

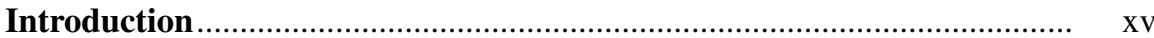

\section{Part I Critical Essays}

1 A Critical Appraisal of Engelhardt on the "Enlightenment Project"

Laurence B. McCullough

2 Diversity in Clinical Ethics. George J. Agich

3 Recognizing the Difference that Faith Makes: H. Tristram Engelhardt, Jr., on Life-Ending Medical Interventions John C. Moskop

4 The Foundations of Secular Bioethics

Stephen Wear

5 Disease, Bioethics, and Philosophy of Medicine:

The Contributions of $\mathbf{H}$. Tristram Engelhardt, Jr.

Mary Ann Gardell Cutter

6 Sanctity of Life: A Study in Ambiguity and Confusion Kevin Wm. Wildes

7 A Transcendental Argument for Agreement as the Sole Sufficient Basis of a Philosophical Ethic

George Khushf

8 Equality Is Problematic: Engelhardt on Fair Equality of Opportunity, Health Care, and the Family

Ruiping Fan 
9 Bioethics After the Death of God - Reflections on an Engelhardtian Theme.

Mark J. Cherry

10 The Ethical Conduct of Research: The Legacy of the Three Principles.

Ana Smith Iltis

11 Non-certain Foundations: Clinical Ethics

Consultation for the Rest of Us

Lisa M. Rasmussen

12 Moral Strangers, Proceduralism, and Moral Consensus 201 Fabrice Jotterand

13 Cracks in the Foundations of Engelhardt's Bioethics 215 Jeremy R. Garrett

\section{Part II Personal Reflections}

14 Two-Score Years Ago 233

Laurence B. McCullough

15 A Recollection with Appreciation. 239 George J. Agich

16 H. Tristram Engelhardt, Jr.-A Personal Reflection 243 John C. Moskop

17 Post-apocalyptic Tris 247 Eric Juengst

18 Ode to Tris 251 Mary Ann Gardell Cutter

19 The Engelhardt Experience 255 Ana Smith Iltis

20 Studying with $H$. Tristram Engelhardt, Jr.: Lessons in an Engelhardtian Weltanschauung. 259 Lisa M. Rasmussen

21 H. Tristram Engelhardt, Jr.: The Man Behind the Scholar 263 Fabrice Jotterand

22 Apprenticing with H. Tristram Engelhardt, Jr.:

A Tribute to the Founder of Our Thing. 265 Jeremy R. Garrett 
23 Dr. H. Tristram Engelhardt, Jr.: Scholar,

Gentleman, Friend

269

D. Christopher Ralston

24 H. Tristram Engelhardt, Jr.: Beloved Mentor

and Teacher

273

Jennifer A. Bulcock

Index.

277 



\section{Contributors}

\section{Corresponding Editor}

Lisa M. Rasmussen, Ph.D. Department of Philosophy, University of North Carolina, Charlotte, NC, USA

\section{Co-Editors}

Ana Smith Iltis, Ph.D. Department of Philosophy, Center for Bioethics, Health and Society, Wake Forest University, Winston-Salem, NC, USA

Mark J. Cherry, Ph.D. Department of Philosophy, St. Edward's University, Austin, TX, USA

\section{Authors}

George J. Agich, Ph.D. Philosophy Department, Bowling Green State University, Austin, TX, USA

Jennifer A. Bulcock Department of Philosophy, Rice University, Houston, TX, USA

Mary Ann Gardell Cutter, Ph.D. Department of Philosophy, University of Colorado, Colorado Springs, CO, USA

Ruiping Fan, Ph.D. Department of Public Policy, City University of Hong Kong, Kowloon, Hong Kong

Jeremy R. Garrett, Ph.D. Children's Mercy Bioethics Center, Children's Mercy Hospital, Kansas City, MO, USA

Department of Pediatrics \& Department of Philosophy, University of Missouri, Kansas City, MO, USA

Fabrice Jotterand, Ph.D., M.A. Department of Health Care Ethics, RueckertHartman College of Health Professions, Regis University, Denver, CO, USA

Institute for Biomedical Ethics, University of Basel, Basel, Switzerland 
Eric Juengst, Ph.D. Center for Bioethics, School of Medicine, University of North Carolina, Chapel Hill, NC, USA

George Khushf, Ph.D. Department of Philosophy, University of South Carolina, Columbia, SC, USA

Laurence B. McCullough, Ph.D. Center for Medical Ethics and Health Policy, Baylor College of Medicine, Houston, TX, USA

John C. Moskop, Ph.D. Department of Internal Medicine, Wake Forest School of Medicine, Winston-Salem, NC, USA

Clinical Ethics Committee, Wake Forest Baptist Medical Center, Medical Center Boulevard, Winston-Salem, NC, USA

D. Christopher Ralston, Ph.D. Christian Institute on Disability, Joni and Friends International Disability Center, Agoura Hills, CA, USA

The Center for Bioethics and Human Dignity, Trinity International University, Deerfield, IL, USA

Stephen Wear, Ph.D. Departments of Medicine, Gynecology-Obstetrics and Philosophy, The University at Buffalo, Buffalo, NY, USA

Center for Clinical Ethics, VA Medical Center, Buffalo, NY, USA

Kevin Wm. Wildes SJ, Ph.D. Loyola University New Orleans, New Orleans, LA, USA 


\section{Author Bios}

George J. Agich co-founded the International Conference on Clinical Ethics Consultation and recently retired as a Professor from the Department of Philosophy at Bowling Green State University. He received his Ph.D. in Philosophy from the University of Texas at Austin in 1976.

Jennifer A. Bulcock is an Assistant Professor in the Department of Philosophy and Liberal Studies at Cabrini College. She earned her Ph.D. from Rice University in 2015.

Mark J. Cherry is the Dr. Patricia A. Hayes Professor in Applied Ethics and Professor and Chair in the Department of Philosophy at St. Edward's University. He received his Ph.D. in Philosophy from Rice University in 1999.

Mary Ann Gardell Cutter is a Professor of Philosophy at the University of Colorado, Colorado Springs. She received her Ph.D. in Philosophy from Georgetown University in 1989.

Ruiping Fan is a Professor of Philosophy in the Department of Public Policy at the City University of Hong Kong. He received his Ph.D. in Philosophy from Rice University in 1999.

Jeremy R. Garrett is a Research Associate at Children's Mercy Bioethics Center, and Assistant Professor of Pediatrics and Adjunct Assistant Professor of Philosophy at the University of Missouri Kansas City. He received his Ph.D. in Philosophy from Rice University in 2008. 
Ana Smith Iltis is an Associate Professor in the Department of Philosophy and the Director of the Center for Bioethics, Health and Society at Wake Forest University. She received her Ph.D. in Philosophy from Rice University in 2003.

Fabrice Jotterand is an Associate Professor in the Department of Health Care Ethics at Regis University and Senior Researcher, Institute for Biomedical Ethics, University of Basel, Switzerland. He received his Ph.D. in Religious Studies from Rice University in 2006.

Eric Juengst is the Director of the Center for Bioethics, and a Professor in the Department of Social Medicine at the University of North Carolina, Chapel Hill. He received his Ph.D. in Philosophy from Georgetown University in 1985.

George Khushf is a Professor in the Department of Philosophy at the University of South Carolina. He received his Ph.D. in Religious Studies/Philosophy from Rice University in 1993.

Laurence B. McCullough is the Dalton Tomlin Chair in Medical Ethics and Health Policy and Professor of Medicine and Medical Ethics at the Center for Medical Ethics and Health Policy, Baylor College of Medicine. He received his Ph.D. in Philosophy from the University of Texas at Austin in 1975.

John C. Moskop is the Wallace and Mona Wu Chair in Biomedical Ethics and Professor of Internal Medicine at the Wake Forest School of Medicine. He received his Ph.D. in Philosophy from the University of Texas at Austin in 1979.

D. Christopher Ralston is the Assistant Manager of Curriculum Development at the Joni and Friends International Disability Center and a Fellow of the Center for Bioethics and Human Dignity at Trinity International University. He received his Ph.D. in Philosophy from Rice University in 2011.

Lisa M. Rasmussen is an Associate Professor in the Department of Philosophy at the University of North Carolina, Charlotte. She received her Ph.D. in Philosophy from Rice University in 2003.

Stephen Wear is an Associate Professor in the Department of Medicine at the State University of New York, Buffalo. He received his Ph.D. in Philosophy from the University of Texas at Austin in 1979.

Kevin Wm. Wildes, SJ is the President of Loyola University New Orleans. He received his Ph.D. in Philosophy from Rice University in 1993. 


\title{
Introduction
}

\section{Introduction}

\begin{abstract}
Alternative moralities compete without an apparent principled basis for definitively choosing one as canonical. If truth cannot break through to us and personally direct us, will we not always be lost in a plurality of diverse moral and religious views in the sense of not knowing which norms should govern? Will morality then be more a matter of taste, cultural inclination, and communal preference? ... Who but a true post-modern could without regret live in such a context? (Engelhardt 2000, xi).
\end{abstract}

Professor H. Tristram Engelhardt, Jr., is a philosopher of difference. The impressive range and depth of his work in philosophy, medicine, bioethics, and theology illustrate his profound appreciation that careful and critical analytical work is central to reigning in the untutored desire to claim established canons of political correctness as truth. Professor Engelhardt's work in the philosophy of medicine, for example, demonstrates the ways in which we see the world through taken-for-granted background social, scientific, and value expectations. What is often thought of as the common scientific world view is set within a web of complex, etiologic forces. Which goals will be pursued, which eschewed? Whose standards of evidence and inference will be adopted? Which will ground knowledge claims? Whose account of the normal versus the abnormal will guide research? And, which group of scientists will function as exemplar knowers? This does not mean that investigators do not attempt to understand reality as it is in itself, unconstrained by cultural, social, and historical forces. Indeed, as Engelhardt points out, the goal of undistorted knowledge functions as a heuristic to direct one towards the truth $(1996,191)$. However, "[o]ur world," as Engelhardt argues, "is structured by a special set of assumptions about the rule-governed character of our experience. These scientific and metaphysical presuppositions fashion for us our everyday expectations. They give shape to our lifeworld" $(1996,190)$. As a result, even those who seek to see truly must be initiated into a particular way of relating to and experiencing reality. One must already have an idea of what truth is and how to find it, as well as how to interpret what one has found. Medical students, for example, have to be taught how 
to "read" the slides they examine under microscopes; researchers must be initiated into the assumptions and practices that guide the experimental methodology of their particular fields. As Engelhardt concludes, the world is simply not furnished with uninterpreted facts.

The circumstance that all knowledge claims are culturally and historically conditioned similarly influences our understandings of morality and bioethics. In his best-known work, The Foundations of Bioethics (1986, followed by a second edition in 1996), Engelhardt laid bare the empirical reality of the deep and intractable moral pluralism of the modern world. In his later theological counterpart, The Foundations of Christian Bioethics (2000), he provided readers with the flip side of this coin: Engelhardt's detailed and serious account of Orthodox Christian bioethics. In each case, Engelhardt concluded that general secular reason is unable to secure a uniquely true account of the right, the good, the virtuous, or the just. It cannot even establish a definitive account of the reasonable or the reliable. As a result, general secular reason is powerless to provide definitive foundations for a content-full secular bioethics, much less settle the deep moral controversies of medicine and health care policy. "In attempts to settle differences by sound rational argument, each side presupposes different fundamental moral premises as well as rules of evidence and inference. Each speaks past the other without a final, rational principled resolution. The result is that bioethical controversies fuel engaging but insoluble debates" (Engelhardt 2000, xi). Consider the seriousness of the challenges at stake: Which account of human nature, and whose explanation of human flourishing and basic goods, should be appreciated as normative? There are even significantly diverse theories for rationally debating the merits of such divergent understandings of human nature. Which consequences should be avoided, which virtues taught, and values embraced, and at what costs to self or others? Whose deep moral intuitions should guide public policy? All attempts to engage particular moral content to guide biomedical decision-making assume what must be proven, argue in a circle, engage in an infinite regress, or otherwise beg the question. ${ }^{1}$ All protestations to the contrary, and in the face of numerous (incommensurable) fashionable claims to bioethical truth, a significant diversity of moral visions, accounts of human flourishing, and accounts of social justice compete to guide moral choice in medicine. Bioethics is, as Engelhardt rightly argues, a plural noun (1996, 3).

Without the ability to know the nature of reality undistorted by historical, cultural, and social context - reality as God would know it to be - the challenges for establishing a uniquely true bioethics to guide public policy are insurmountable. All one can know with any certainty is one's own experiential phenomenological world; but this is split into numerous competing accounts of phenomenological reality,

\footnotetext{
${ }^{1}$ As Engelhardt is well aware the problems that beset secular philosophical analysis have been known for millennia. Consider, for example, Sextus Empiricus (A.D. 160-210) on the Outlines of Pyrronism: "The more recent Skeptics hand down the following five modes of epoché: the first is the mode based on disagreement; the second is that based on infinite regress; the third, that based on relativity; the fourth, on hypothesis; and the fifth is the circularity mode" (Sextus Empiricus 1996, I.164).
} 
each of which is itself socially, historically, and culturally conditioned. Given such abiding and significant moral pluralism, Engehardt argues that secular moral authority must be created through and, therefore, is limited to, the actual agreements among actual persons. General secular morality, and thus secular bioethics, is libertarian by default - not because of any particular celebration of liberty as a value, nor due to any fantastic assumptions regarding the basic human rights of persons, but as a default moral and political reality. The norms that we ourselves create with free and consenting others, and strictly limited to the extent of such agreement, provide for the possibility of binding together moral strangers into morally authoritative common projects. General secular morality is created, rather than discovered.

In many circles, Engelhardt is perhaps best known for this unflinching libertarianism. Indeed, it is widely assumed that Engelhardt affirms not only the libertarian political framework of his conclusions, but also its frequently libertine personal consequences. As Ana Iltis and Mark Cherry remarked on another occasion: "Many (perhaps most) readers have not taken seriously Engelhardt's own announcements found throughout the two editions of The Foundations of Bioethics that general secular morality permits and justifies many activities that he, himself, knows to be deeply sinful (e.g., abortion on demand, human embryonic stem cell research, euthanasia, same gender marriage, and so forth) as well as imprudent (utilizing a chiropractor or doctor of naturopathy for treatment of heart disease)" (Iltis and Cherry 2010,2). The core challenge, as Engelhardt has argued in great depth, in numerous countries, on many continents, in a wide variety of formats, including lectures, commentaries, articles, book chapters, book-length monographs, and other publications too numerous accurately to count (over years too lengthy for it to be polite to mention), is that there simply does not exist secular moral authority permissibly to prohibit such actions among consenting persons.

At the Foundations of Bioethics and Biopolitics: Critical Essays on the Thought of H. Tristram Engelhardt, Jr. engages Engelhardt's diagnosis of the limits of secular reason and moral political authority, as well as his search for ultimate foundations. This is a book by Engelhardt's students. Over the courses of our various and diverse careers, Professor Engelhardt has nurtured each of us into scholars in our own right. None of the chapters is merely laudatory. Each carefully addresses, explores, and critically assesses key elements of Professor Engelhardt's philosophical labors. Many, if not all, raise objections, make careful distinctions, or argue with core aspects of the Engelhardtian project. Some engage his arguments in the bioethics and philosophy of medicine, others in clinical ethics, still others in the history of ideas, social and political philosophy, or international bioethics. One finds essays across the moral and political spectrum. A few of his students have been willing to bite the bitter pill of post-modernity and accept as its consequence libertarianism by default; a few, indeed, have been willing to convert to Orthodox Christianity. But, such diversity is as it should be for a professor who has had such an immense and international impact on the fields of philosophy, medicine, bioethics, and theology. Our hope in presenting this volume to an international audience is to celebrate a singularly distinguished career marked by an extraordinary depth and breadth of scholarship, together with inspiring and engaging teaching, as well as exceptional generosity and love to his students. 


\section{Critical Essays}

In "A Critical Appraisal of Engelhardt on the 'Enlightenment Project'," Laurence B. McCullough challenges the history Engelhardt customarily offers of a single enlightenment and argues that there were actually multiple "enlightenment" projects. In the English and Scottish versions of the project, McCullough argues, the aim was not a quest for certainty grounded in mere reason, but rather "a quest for reliability." In their "moral science," English and Scottish enlightenment thinkers focus variously on sympathy and intuition rather than certainty or the primacy of reason. As a result of his focus on one strand of Enlightenment thought, McCullough argues, Engelhardt ignores another option for bioethics' search for moral foundations, that of a "reliable" morality that does not require certainty. It is just such a "reliable bioethics" that McCullough recommends.

In "Diversity in Clinical Ethics," George J. Agich argues for the centrality of diversity (understood multi-dimensionally, including value and practice diversity) to the field, not just in terms of having helped drive its creation, but also as an internal feature that must be incorporated into the practice. This diversity exists in conceptual and theoretical considerations of the practice as well as in the very structures and processes of the practice. Agich expresses a worry that diversity is sometimes taken to be a mark of a field's immaturity, and, in clinical ethics consultation in particular, this worry contributes significantly to the drive to professionalize the field. Instead, Agich argues, diversity is valuable to the field as a basic characteristic of the practice and as a resource for improvement in the practice. Moreover, and crucially, the deep value pluralism within which clinical ethics consultation is practiced (and which is a deep well of Engelhardt's thought) is too casually treated as a marginal problem "rather than as an essential feature of the field that needs to be understood" (Chap. 2, this volume, p. 15). The field seems engaged in a blind and undefended search for consistency, Agich points out, when instead it should understand, embrace, and incorporate diversity in various ways.

John C. Moskop, in his chapter, "Recognizing the Difference that Faith Makes: H. Tristram Engelhardt, Jr., on Life-Ending Medical Interventions," examines some of Engelhardt's contributions to discussions of end of life care, especially debates concerning the permissibility of employing life-ending medical interventions. Moskop notes that in the secular literature, Engelhardt has defended the right of physicians and patients to employ life-ending medical interventions. Yet Engelhardt rejects the permissibility of life-ending medical interventions in his work in Christian bioethics. Moskop examines Engelhardt's scholarship on life-ending medical interventions from a secular and Christian perspective, comparing the two positions and considering the extent to which they are consistent. He argues that there are ways in which Engelhardt's positions may be understood as consistent with one another. Nevertheless, "the shift in emphasis in his writing from endorsement of individual rights to employ these interventions, to religiously inspired condemnation of any form of medical killing, is a remarkable development in his thought." 
Stephen Wear, in "The Foundations of Secular Bioethics," assesses Engelhardt's arguments regarding the failure of the Enlightenment and the implications of this failure. The Enlightenment failed to rationally secure a content-filled, lexically ordered secular morality. As a result, Engelhardt argues that we are left with a minimalist account of ethics focused on the ethics of permission between moral strangers. Wear challenges Engelhardt's view that secular bioethics can give us nothing more than the ethics of permission. With a focus on clinical ethics, Wear argues that "a substantial, secular ethic can be (and has been) legitimately fashioned that provides respectable, coherent guidance for moral strangers." Wear argues that there is room between Engelhardt's libertarian ethics of permission and its opposite, the liberal cosmopolitan view (which both Wear and Engelhardt reject), for a more satisfying account of ethics. This account, Wear demonstrates, is substantive and has been developed through "decades of substantial argument, debate, and experience." It is not impoverished, he says, in the ways Engelhardt would have us believe.

Mary Ann Gardell Cutter reviews Engelhardt's significant contributions to the philosophy of medicine in "Disease, Bioethics, and Philosophy of Medicine: The Contributions of H. Tristram Engelhardt, Jr.," arguing that one of the most notable features of his work in this area is the demonstration of the interreliance of bioethics and philosophy of medicine. In demonstrating, via Engelhardt's work, that the bioethical implications of concepts like "disease" are framed in terms of particular epistemological and ontological commitments articulated in the philosophy of medicine, Gardell Cutter shows that philosophy of medicine is, and should be, always present in the study of bioethics.

Much of Engelhardt's work has addressed the differences between Christian and secular bioethics as well as differences among religious approaches to bioethics. The contribution from Kevin Wildes, SJ, "Sanctity of Life: A Study in Ambiguity and Confusion" (reprinted from an earlier volume), demonstrates the significance of such differences with respect to the term "sanctity of life." The term, frequently deployed by secular bioethicists, was first used in religious contexts and, Wildes argues, cannot so easily be repurposed as these secular uses suggest. Using the term "sanctity of life" as a heuristic, Wildes demonstrates this failure by comparing just two religious interpretations of it, from Christian and Buddhist traditions. He shows that not only do these religions conceive of the term differently from each other, there are also diverse possible interpretations within each tradition. Each can lead to different conclusions about what kinds of lives have this "sanctity," and with what other values this sanctity can be balanced. And so, he argues, "when such terms are taken from their basic role they yield very little" (Wildes, Chap. 6, this volume, 84).

George Khushf takes on a significant portion of Engelhardt's corpus in order to articulate the many and complex lines of argument woven throughout. In "A Transcendental Argument for Agreement as the Sole Sufficient Basis of a Philosophical Ethic," Khushf explores one of the most central and famous arguments in Engelhardt's work, the "Principle of Permission," which Engelhardt argues provides both a minimal and sufficient condition for the possibility of secular morality. Khushf's tour de force necessarily explores what he calls "argumentative strands" 
in Engelhardt's work in order to reconstruct the transcendental argument presented in the Foundations of Bioethics (2nd ed.). Along the way, he also investigates the meaning of terms such as "agreement," "conflict," "basis," etc., which factor centrally in the transcendental argument. This demanding essay pays rich dividends for those who want to understand or challenge Engelhardt's work, for it is the only work the editors know of which attempts to bring so many of Engelhardt's claims and argumentative pathways together in order better to understand the whole.

Ruiping Fan focuses on Engelhardt's arguments regarding the requirement for a fair equality of opportunity in "Equality Is Problematic: Engelhardt on Fair Equality of Opportunity, Health Care, and the Family." These arguments, Fan notes, demonstrate that contestable values underlie every conception of fairness or equality upon which a social democracy might base a health care system. As a result, the moral legitimacy of a single-payer health care system is in question. Worse, Fan argues, the reliance on the Rawlsian principle of fair equality of opportunity may undermine the integrity of the traditional family. Because the family is a fundamental source of "nonegalitarian intergenerational obligations," it may come under siege from egalitarian movements. With Engelhardt, Fan argues that the establishment of the modern social welfare state has already contributed to an erosion of the family.

In "Bioethics After the Death of God - Reflections on an Engelhardtian Theme," Mark J. Cherry explores ontological issues in bioethics that result from the lack of canonical moral foundations Engelhardt articulates. Epistemically, Cherry argues, canonicity requires a God's-eye perspective, but modern secular morality cannot achieve such a perspective. Lacking that perspective, he argues, any claims to moral values without God or a God's-eye perspective will simply reveal prevailing tastes rather than timeless truth. So, to the extent that bioethicists claim authority to guide public policymaking and clinical decisions, what they in fact provide is "their own idiosyncratic criteria for veracity, rationality, and reliability, as well as rationalizations for ideologically driven political advocacy" (Cherry, Chap. 9, this volume, 159-175).

In her chapter, "The Ethical Conduct of Research: The Legacy of the Three Principles," Ana Smith Iltis explores Engelhardt's early contributions to discussions regarding the ethical conduct of research. Engelhardt was among the scholars who wrote background papers for the National Commission for the Protection of Human Subjects of Biomedical and Behavioral Research. In his contribution, Engelhardt argued that human research must respect three principles. The National Commission ultimately adopted three principles, the first two of which bear a resemblance to Engelhardt's first two principles. In articulating three principles, Engelhardt addressed the relationship among them. He argued that the first principle, which required respect for "human subjects as free agents," was prior to the other two principles. His second and third principles involved obligations to "foster the best interest of the individual human subjects" and to "maximize the benefits accruable to society from research" (Engelhardt 1978, pp. 5-6). Engelhardt argued that the principles were not all equal and unranked but rather that the first took precedence over the other two. The National Commission was not as explicit as Engelhardt was in addressing the relationship among the principles it articulated. The subject of 
whether the three principles stipulated in the Belmont Report, respect for persons, beneficence, and justice, are unranked, equally important principles or whether there is some other relationship among them continues to be debated. Iltis explores this debate and the significance it has for contemporary discussions in research ethics.

Lisa M. Rasmussen focuses on Engelhardt's critiques of clinical ethics consultation in "Non-Certain Foundations: A Clinical Ethics Consultation for the Rest of Us." She summarizes arguments found in a number of Engelhardt's works, particularly the history he offers to explain the rise of the field. Even accepting that history, Rasmussen shows, does not require drawing the same conclusions Engelhardt does regarding the legitimacy of the field. But further, she argues, the conclusions he draws are themselves reliant upon metaethical premises which can be countered with other possible premises. In particular, she focuses on Engelhardt's assumption that certainty provides the only possible justification for moral claims. Similar to McCullough's observations (Chaps. 1 and 14, this volume), she articulates what "non-certain" justification might look like in clinical ethics consultation, but also acknowledges that many of Engelhardt's recommendations for changes in the practice of clinical ethics consultation are correct and must be addressed.

Fabrice Jotterand explores a question that has consumed much of Engelhardt's scholarly work: in the ruins of the Enlightenment and in the face of irreducible moral pluralism, how may one "rebuild and provide moral guidance to social practices such as medicine, science, and technology despite moral pluralism and the incommensurability of current bioethical debates." As Jotterand notes, Engelhardt diagnosed a fatal problem with modernity and deconstructed its philosophical agenda. The chapter reflects on the implications of this diagnosis as Engelhardt characterizes them, raising critical points concerning the notion of moral strangers and procedural ethics Engelhardt describes.

Jeremy R. Garrett explores the tension between the critical and constructive elements of Engelhardt's work on the foundations of secular bioethics in "Cracks in the Foundations of Engelhardt's Bioethics." He argues that the nature, scope, and depth of Engelhardt's critiques of the "prevailing methods and values of (secular) bioethical discourse" threaten to undermine even his own positive project of anchoring bioethics to the (purportedly) value-free, content-less, default-justified principle of permission. This tension, Garrett argues, reveals a number of significant "cracks" in the foundations of Engelhardt's bioethics, "each tracing back to fundamental underlying assumptions embedded in his view." These cracks already surface when Engelhardt's framework treats paradigm cases in bioethics (i.e., interactions between fully mature, independent, and autonomous individuals), but expand dramatically when this same framework is applied to non-paradigm cases, including standard cases in pediatric bioethics. Garrett concludes that Engelhardt's framework cannot withstand the internal tension between its critical and constructive elements, but instead is pushed either toward a nihilistic rejection of all (secular) morality or toward a thick content-full bioethics.

Finally, the volume concludes with a special section of personal essays. In our experience, there seems to be a reflected branding involved in being one of 
Englhardt's students. Having misunderstood the man himself, people can sometimes misunderstand what it what it was like to be one of his students, or what it continues to mean to have been one of his students. It is a pleasure, with this final set of essays, to offer a fuller picture of studying with our mentor, Professor Dr. H. Tristram Engelhardt, Jr.

\section{Conclusion: The Plantation}

Because of our inability rationally to defend a canonical correct, concrete moral order or in general secular terms to establish the moral authority coercively to impose a particular concrete moral vision, and because of the ever-available moral standpoint of consensual association based on permission, we have a morality that allows many moralities to be and have their place. In the ruins, even with moral strangers, we can meet and collaborate with moral authority (Engelhardt 1996, 422).

Over the decades, Professor Engelhardt developed a peculiar and very Texian language for describing the relationship among himself and his students: The Plantation. Even though his earliest students will insist that in their time he had not yet fully developed such a robust description, it remains a plausibly descriptive term for all of us who have so labored. There has been much work to be done: two international academic journals: The Journal of Medicine and Philosophy (Oxford University Press) and Christian Bioethics (Oxford University Press); two major book series: Philosophy and Medicine (Springer) and Philosophical Studies in Contemporary Culture (Springer); classes to teach on philosophy, health care policy, medical ethics, and ICU ethics rounds; articles to review; books to write; lectures to present; national and international conferences to organize; travel to manage throughout the United States and to many cities abroad; research to engage; good scotch, fine wine, and the occasional James Bond martini to be drunk; and even sometimes a dog that needed to be fed. Excellence would be insisted upon. No excuses. Sleep, a luxury to be frowned upon. In exchange, Professor Engelhardt's obligation was to work tirelessly for his students, not simply through the drafting of a dissertation and successful defense of their PhDs, but until each had obtained the rank of Full Professor with tenure, and even thereafter to continue to support their careers.

Many of Professor Engelhardt's students were and are moral strangers to him and with each other:

\footnotetext{
Moral strangers are persons who do not share sufficient moral premises or rules of evidence and inference to resolve moral controversies by sound rational argument, or who do not have a common commitment to individuals or institutions in authority to resolve moral controversies. A content-full morality provides substantive guidance regarding what is right or wrong, good or bad, beyond the very sparse requirement that one may not use persons without their authorization $(1996,7)$.
}

This fact has never meant that they could not be affective friends. It has never implied that they could not meet and collaborate with moral authority. As Professor Engelhardt's students, we share a bond that is deep and significant, but impossible adequately to convey to others. We have shared friendships, common experiences, 
and, perhaps, a bit of post-traumatic stress disorder. Not once in the many years that we have known him, however, has Professor Engelhardt ever strayed from or ceased aggressively to pursue his duties to his students. The depth of his professional energies has always been the greatest when he has sought to help his students and their projects. Here one might recall G.W.F. Hegel's argument that philosophy justifies itself within a circle of thought: the more encompassing the circle, the more powerful and commanding the explanation (Hegel 1975 [1830], sec 17). The Plantation is a powerful circle of thought, indeed.

Charlotte, NC, USA

Winston-Salem, NC, USA

Austin, TX, USA
Lisa M. Rasmussen

Ana Smith Iltis

Mark J. Cherry

\section{References}

Engelhardt Jr., H.T. 1986. The foundations of bioethics. New York: Oxford University Press.

Engelhardt Jr., H.T. 1996. The foundations of bioethics, 2nd ed. New York: Oxford Unviersity Press.

Engelhardt Jr., H.T. 2000. The foundations of Christian bioethics. Lisse: Swets \& Zeitlinger.

Engelhardt Jr, Tristram H. 1978. Basic ethical principles in the conduct of biomedical and behavioral research involving human subjects. In National commission for the protection of human subjects of biomedical and behavioral research, The Belmont Report, Appendix II, 8.1-8.45.

Hegel, G.W.F. 1975 [1830]. The encyclopedia of the philosophical sciences, 3rd ed. Trans. William Wallace, forward by John Findlay. New York: Oxford University Press.

Iltis, A, and M.J. Cherry. 2010. Introduction: At the foundations of Christian bioethics; or, why H. Tristram Engelhardt Jr.'s Christian bioethics is so very counter-cultural. In At the roots of Christian bioethics: Critical essays on the thought of H. Tristram Engelhardt, Jr. ed. A.S. Iltis and M.J. Cherry. Boston: Scrivener Publishers.

Sextus Empiricus. 1996. Outlines of Pyrronism. Trans. with Introduction and Commentary, Benson Mates. New York: Oxford University Press, 1996. 